\title{
The 7+ Habits of Highly Effective Medical Directors
}

\author{
Alexander Bedenkov ${ }^{1} \cdot$ Viraj Rajadhyaksha $^{1}$ [D $\cdot$ Carmen Moreno $^{2} \cdot$ Susana Goncalves $^{3} \cdot$ Pei-Chieh Fong $^{4}$. \\ Andrey Ipatov ${ }^{5}$ Berin Erdal ${ }^{6}$
}

Accepted: 24 August 2021 / Published online: 19 September 2021

(c) The Author(s) 2021

\begin{abstract}
Medical Directors in the pharmaceutical industry are responsible for fulfilling multiple roles, including scientific expert, conscience keeper and people leader, as well as being the external face of the organisation. The capabilities described in the book The 7 Habits of Highly Effective People ${ }^{\circledR}$ are not just the integral qualities of a successful leader, they are important capabilities that are critical to becoming an impactful medical leader too. As scientific, functional and enterprise leaders, country and cluster Medical Directors must possess these seven qualities. Each of the seven habits can be adapted and utilised to shape the specific areas that Medical Directors are responsible for: intuitive creativity, patient centricity, prioritisation, enterprise leadership, communication and behavioural change, building a team, partnering and scientific and technological leadership. To excel in their function, current and future Medical Directors need to sharpen their existing skills and build specific capabilities. Energy management in physical, mental, emotional and spiritual domains is the way forward.
\end{abstract}

\section{Key Points}

The 7 Habits of Highly Effective People ${ }^{\circledR}$ can be incorporated into the Medical Director role.

Medical Directors should possess these seven qualities in order to successfully make an impact in their role.

Current and future medical leaders need to develop their capabilities in order to excel in each of these seven areas, including energy management in physical, mental, emotional and spiritual domains.

Viraj Rajadhyaksha

viraj.rajadhyaksha@astrazeneca.com

1 AstraZeneca Medical, International Region, Luton, UK

2 AstraZeneca Medical, International Region, Madrid, Spain

3 AstraZeneca Medical, International Region, Buenos Aires, Argentina

4 AstraZeneca Medical, International Region, Taipei, Taiwan

5 AstraZeneca Medical, International Region, Moscow, Russian Federation

6 AstraZeneca Human Resources, International Region, Luton, UK

\section{Introduction}

Medical Affairs is now the cornerstone function in the pharmaceutical industry [1-3]. Changes in regulations, expectations of internal and external stakeholders and types of portfolio have resulted in the evolution of the function [4]. The pharmaceutical industry operates through multiple offices across multiple countries, and sometimes in clusters of more than one country. Typically, a Medical Director leads the Medical Affairs department, although specific designations can vary subject to the organisation or geography.

Historically, Regulatory, Clinical Research, Pharmacovigilance and Medical Affairs have emerged from the same team. However, in recent times, the rapid evolution of Medical Affairs has made it the most prominent, strategic and standalone function in a country.

This article is mainly focused on Medical Directors leading the Medical Affairs function at country or cluster level, although broad principles can be applied to Medical Directors performing many other regional or global roles. Overall, the role of a Medical Director can be categorised into four clear quadrants (as demonstrated in Fig. 1): as a scientific expert, a conscience keeper, the external face of the organisation and a people leader [5]. 
Fig. 1 The four quadrants of the Medical Director role

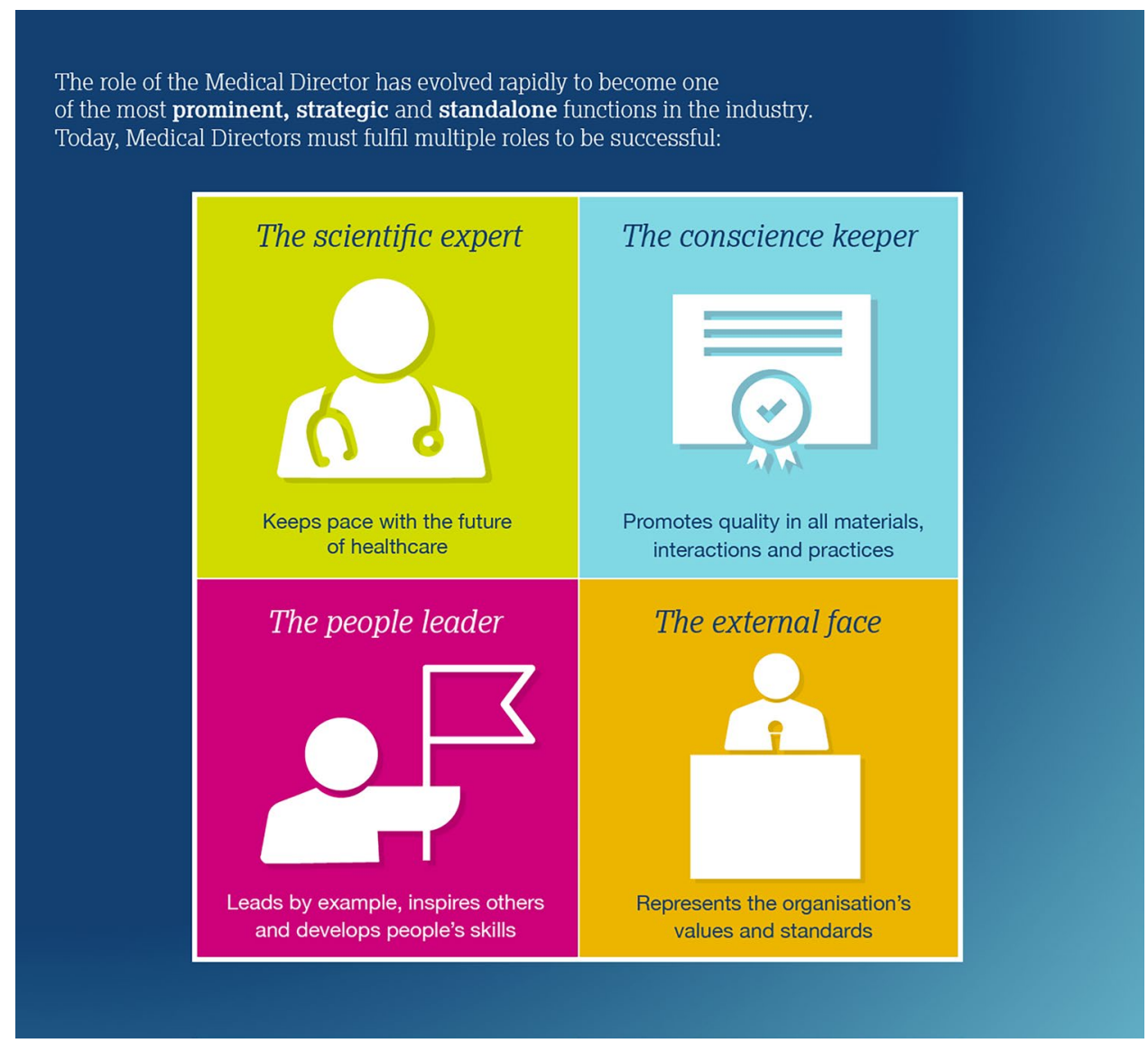

The scientific expert: Rapid advancements in science have led to specialised medicines becoming an important portfolio for most pharmaceutical organisations. Additionally, our understanding of disease biology and the development of personalised medicines has deepened further. The Medical Director, therefore, must have in-depth expertise in disease management and an aptitude and interest in at least one clearly defined therapeutic area, understanding how future therapies will evolve. From a practical standpoint, they also need to be aware of the important role of payers and insurance companies, and cognisant of the challenges that patients and caregivers face. As a result of this, the Medical Director should be perceived as a scientific expert and strategist, both internally and externally. The conscience keeper: In most organisations operating across emerging markets, the Medical Director or designee functions are the final signatory for all materials that are shared externally. In addition, interactions with health care professionals (HCPs), payers and insurance companies, patients and representatives are led by the Medical Affairs team in general, with the Medical Director ultimately held accountable. The role of the Medical Director must be to ensure that governance processes are robust and streamlined, and that the individuals responsible for these processes are well informed of the regulations and assertive enough to implement them. The Medical Director must have an in-depth knowledge of local laws and regulations related to the promotion of medical products and interactions with HCPs. With the arrival of social media and a higher number of digital channels of communication, this has now become even more complex than before. There are certain practices for Medical Directors to engage via social media platforms. For example, posting content relating to disease awareness is allowed in many cases, however sharing or even 'liking' content that relates to drugs or drug-related data may be perceived as promotional or an endorsement and is therefore to be avoided. Additionally, in some organisations, Medical Directors are also in charge of assuring adherence to quality (good clinical, regulatory, pharmacovigilance, manufacturing and distribution practices). In this way, we can affirm that Medical Directors are the guardians of maintaining the Licence to Operate for their affiliates.

The people leader: A major responsibility of the Medical Director is leading a team of diverse people. As the Medical Affairs function has evolved to become a key strategic pillar, and Medical Affairs teams are expanding and becoming more specialised, the Medical Director needs to develop new skills and capabilities in their 
teams, provide opportunities for development and guide team members with their own professional expertise. This responsibility has emerged as one of the most critical success factors for a Medical Director. On the other hand, the Medical Director also plays a leadership role in senior management teams at country, cluster or regional level, and this role also involves leading the team in both patient-centric and scientifically driven directions. The Medical Director needs to lead by example, inspire other colleagues and navigate a complex matrix environment. Bringing out the best in people is a key result area for measuring the success of Medical Directors.

The external face: In an age where external partnerships are key to success, Medical Directors play the important role of representing their organisation in a very scientific, unbiased manner, partnering with medical societies and associations and payer/insurance organisations to improve diagnosis, early identification of patients and optimum management. They need to add value to multiple stakeholders-including governments, reimbursement agencies and policy makers-while representing the organisation's values and positioning their standards in the right way. They also need to be adept at speaking to the media as the designated spokesperson for their organisation. Medical Directors should be seen as the scientific and strategic partner of choice by all external stakeholders.

Another important aspect for a Medical Director is being an enterprise leader outside of their own function. We will discuss a few aspects of this role within this article, in addition to what we believe constitute the seven+ habits of a highly effective Medical Director.

\section{The 7 Habits of Highly Effective People ${ }^{\circledR}$ : how they apply to Medical Directors}

There are various frameworks that measure success and effectiveness as people, and more specifically as leaders. One of these frameworks, which is widely acknowledged and applied, is Stephen Covey's concept of The 7 Habits of Highly Effective People ${ }^{\circledR}$, which came to prominence in 1989. Covey postulated that seven habits (Be Proactive $\AA$; Begin With the End in Mind $₫$; Put First Things First ${ }^{\circledR}$; Think Win-Win ${ }^{\circledR}$; Seek First to Understand, Then to Be Understood ${ }^{\circledR}$; Synergize ${ }^{\circledR}$; Sharpen the Saw $\left.{ }^{\circledR}\right)$ would be essential factors for leaders to succeed in their role, as well as develop further [6]. These habits are universal and unrelated to functional domain, and they have stood the test of time. We feel that these habits should be specifically incorporated into ways of working for Medical Directors in order for them to be successful in their current role and evolve their function in the future. In the sections below, we have highlighted how each of these seven habits (and one more) add value to a specific function or role that Medical Directors play (Fig. 2). Additionally, we have also shared some examples of how these habits have been practised in recent times.

\subsection{Be Proactive $^{\circledR}$ : Intuitive Creativity}

The future of the Medical Affairs function, and the health care industry at large, needs leaders who create change, rather than manage it. There are basic skills that work effectively within the conventional leadership paradigm [7], such as the ability to communicate a vision, adapt to multiple personalities, manage conflict and motivate a team. In this case, a Medical Director's effectiveness as a leader is primarily a function of what they have learned and achieved in the past, and how their past learnings impact their present effectiveness. However, the highly effective Medical Director's future is in driving their present. Their effectiveness as a leader also depends on how they prepare to address future challenges [8]. That is why, in addition to basic skills, a Medical Director needs to upskill and develop new skills to inspire their teams to 'create the future'. Intuitive creativity is a high priority. This skill is the blend of heightened intuition with highly refined listening skills, along with the ability to link creative solutions to what is understood [7]. Steve Jobs, co-founder of Apple and one of the most creative leaders in the world, was accurate in describing the phenomenon: "Creativity is just connecting things. When you ask creative people how they did something, they feel a little guilty because they did not really do it, they just saw something. It seemed obvious to them after a while" [9].

The key to intuitive creativity is the ability to be [10-13]:

- Open.

- A master listener.

- A learning zealot who learns something new every day.

- A customer fanatic-patient-centric (driven by improving experiences and ensuring better outcomes for patients) while also committed to supporting the diverse needs of other stakeholders, including HCPs and payers.

- Technologically savvy - in addition to mastering one of the therapeutic areas to 'key opinion leader level', thinking across multiple therapeutic areas and industries, and most importantly, the ability to leverage technology within disease areas, exploit technological advances and disruptive technologies (including medical analytics/ voice-of-customer analyses).

- A personal disruptor, knowing when to disrupt yourself.

- A tough-minded optimist.

- An eager experimenter, supporting multiple ideas to find a few that work. 
Fig. 2 The 7+ habits of highly effective Medical Directors

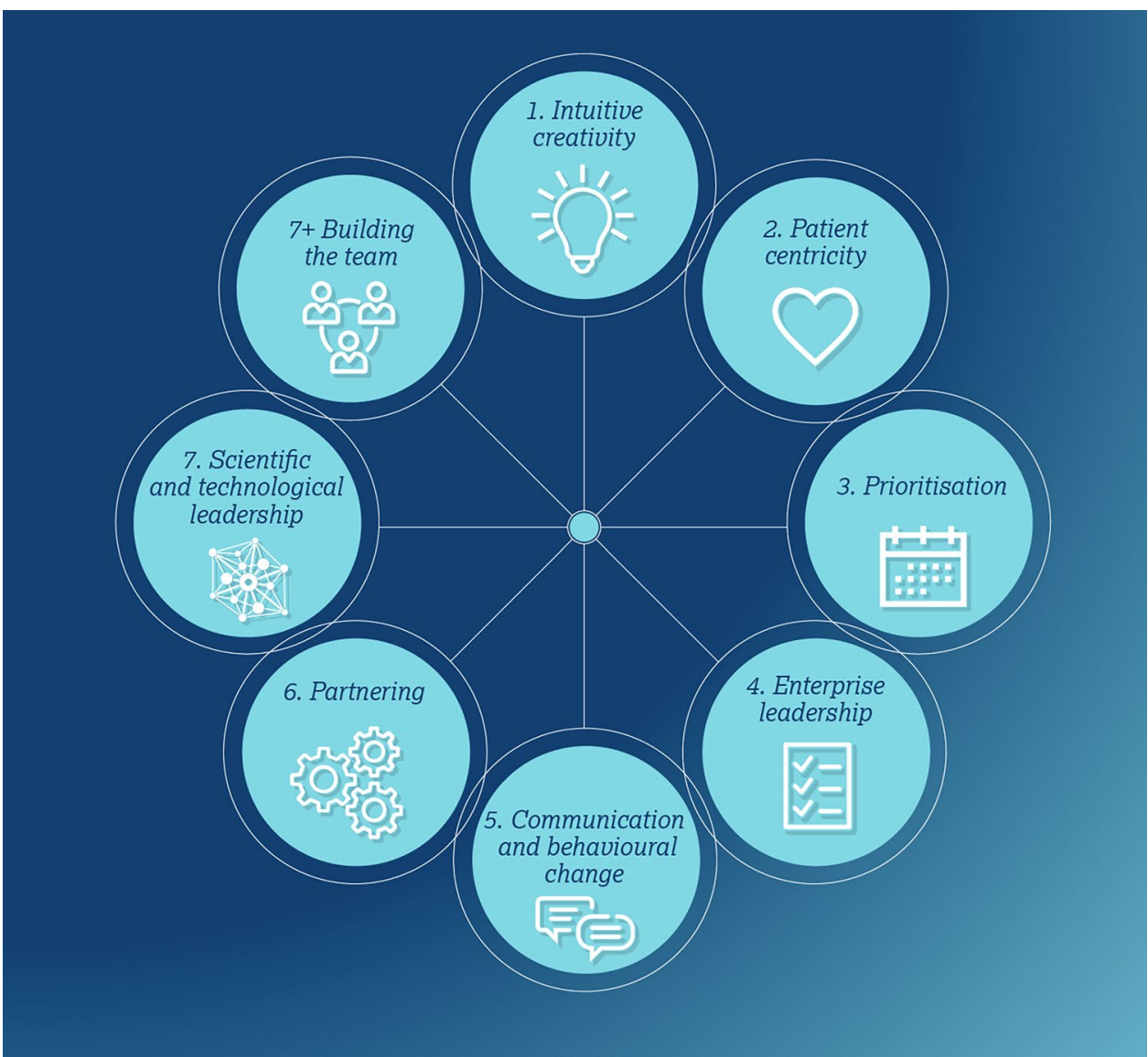

In addition, based on our experience, the most creative Medical Directors have a broader base to their career ladder from transferring between functions and departments, providing a wider set of experiences and knowledge and serving as a solid foundation for creativity to build on.

Another important aspect for an effective Medical Director is to continuously support a culture of creativity within their medical teams. Creating a safe environment in the workplace is important for supporting the team's creativity; Medical Directors must take reasonable risks to allow team members to fail while experimenting with new approaches. Both attraction and retention of creative talents and cognitive diversity within the team will also help foster creativity. Creativity should become a strategy in itself and be part of every Medical Affairs function-not just related to a specific therapy area. It should also be an integral part of traditionally conservative areas, such as License to Operate (medical compliance, patient safety, medical information).

To conclude, we come back to one of the most creative leaders and teams in the world-Steve Jobs and the Macintosh Design Team. Another important lesson we have learned from them about creativity (and have adapted to our needs in AstraZeneca's International Medical team), is the application of the following principles [14]:
- Active participation: It does not matter how great the planned Medical Affairs activity is - if nobody wants to participate in it, it will not garner the expected creative output.

- Cost effectiveness: We should aim to maximise activities with optimum resources so that as many HCPs and patients as possible can participate in-and benefit from-the activity.

- Diversity and excellence: Find the best people from anywhere in the industry and company to support the initiative.

- Create the new normal: 'Blow people's minds' and overturn and create new standards; do not do the same things as everyone else.

- Be resourceful: We do not have to invent everything-we are happy to adopt great approaches from others.

\subsection{Begin with the End in Mind ${ }^{\circledR}$ : Patient Centricity}

Putting patients at the centre of a pharmaceutical industry strategy is probably the most specific or even intuitive habit of a Medical Director. To be effective in this aspect, Medical Directors should be able to draw on their technical background in medical science and disease understanding, as well as art-of-medicine skills, acquired during clinical 
practice. Medical Directors should leverage both their background and skills to influence different functions in the implementation of their strategy. This way, they can deliver the outcomes and health care experiences that people care most about and support patients to help them enjoy fulfilling lives. Patient centricity means understanding and fulfilling both objectives. Medical Directors are equally responsible for delivering the best patient experiences and outcomes. If they deliver excellence in just one aspect, but not the other, they will be failing in their most important responsibility as guardians of patient wellbeing.

In order to truly make patient centricity a habit, Medical Directors should ensure that both aspects are incorporated in the strategy for each disease area that they are responsible for, and track that their teams are doing the same.

\subsubsection{Ensuring the Best Outcomes for Patients}

To achieve the objective of delivering the best patient outcomes, a Medical Director needs to be not only an expert in the data around the product they manage, but also an expert on the disease state itself. This includes the pathophysiology, epidemiology, clinical data across several treatment options and standards of care in the specific geographical area. There are three practices that help in exercising this habit:

Medical Directors Should Invest Time in Reading and Understanding Scientific Journals: Ideally two or three reviews of the latest developments within the disease area from relevant internal medicine journals. This will help Medical Directors comprehend the current understanding within the general medical community. It is also important that Medical Directors read publications concerning their own products. Finally, reading publication results from other therapeutic options will help Medical Directors understand the difference in populations and results, and enable them to compare how applicable they are to their own context.

Medical Directors Should Meet and Discuss Their Practice Directly with Two or Three Specialists Quarterly: During these conversations, it is important for Medical Directors to ask questions about how patients receive information, how they engage with diagnosis procedures and treatment indications and how the health care system is prepared for caring for these specific patients. This will help Medical Directors to monitor their own understanding of the science and the current practice of medicine in their own ecosystems and will also ensure they are asking the right questions, using the latest terminology and, most importantly, building their own network.

Medical Directors Should Take Time to Meet and Engage Directly with Patients: To understand their needs and how they feel about their treatment journey, enabling them to act on their insights and deliver innovative approaches that improve outcomes. Medical Directors should participate in patient advisory boards, meet with patient advocacy groups (PAGs) or obtain insights from social listening. One practice Medical Directors may find beneficial is spending a full day with patients and care givers. This has been adopted in some areas with excellent results, not only for the medical team, but for other members of the cross-functional team as it provides valuable first-hand insights into patients' needs.

\subsubsection{Ensuring the Best Health Care Experience for Patients}

When aiming to provide the best patient experiences, a Medical Director should be concerned about the uptake of screening, diagnosis, procedures and treatments, and how uptake can directly affect patient wellbeing, as well as outcomes. A Medical Director should challenge how established standards of care can be improved to yield even better patient experiences and enhance outcomes in the future. There are a number of actions to incorporate this habit:

Medical Directors Should Take Time to Understand the Reality of Their Ecosystem and Shape it to Exceed Expectations: They should ensure research on the capabilities and capacities available complies with the standard of care requirements. They should identify the gaps, including patients' perspectives, and look for partners that may have a shared interest in enhancing these capabilities and capacities. It is important to ensure any partners understand and incorporate patients' needs as well.

Medical Directors Should Build Their Strategy Ensuring they have Listened to and Incorporated the Voice of the Patients: From clinical trials and real-world evidence (RWE) studies to educational programmes and disease awareness campaigns, Medical Directors should check that all aspects related to patient wellbeing are being incorporated, as well as any instances for adjustments based on patient insights and real-time results.

Medical Directors Should Provide Support in Navigating Chronic Diseases, Beyond Medical Aspects, and Help Ensure Equitable Access: They should play a role in ensuring awareness campaigns are reaching the right population with the right approach, and that disease screening complies with Frame and Carlson criteria. Furthermore, they should deliver an avoidable complications approach, and maintain diagnostic and treatment options availability and affordability.

Medical Affairs is uniquely positioned at the centre of the interaction between the patient, medicine, health technology and the health care ecosystem to bridge the gap between them and lead a revolution in improving outcomes for patients.

The Medical Director should act internally as the voice of the patient to shape strategy and provide patient value. In this way, the Medical Director, acting like an orchestral conductor, brings together people from different functions, 
encouraging the development of a patient-immersed culture that supports cross-functional team knowledge sharing, decision making and collaboration, fostering innovative health care solutions for better patient outcomes and experiences.

\subsection{First Things First ${ }^{\oplus}$ : Prioritisation}

With increased capabilities and responsibilities come increased expectations, a higher number of stakeholders and different types of collaboration that go beyond the traditional Medical Affairs function, without replacing any of the basic responsibilities. It is easy for the Medical Director to feel overwhelmed with the number of tasks that await them and prioritising their to-do list may seem like an impossible task. However, as the author of The 7 Habits of Highly Effective People ${ }^{\circledR}$, Stephen Covey, states, "the key is not to prioritise what is on your schedule, but to schedule your priorities" [15]. Prioritisation based on importance and urgency is no longer sufficient. The ability to 'deprioritise' is just as important-removing tasks from the list and aligning all internal stakeholders on the decision. The prioritisation of an effective Medical Director should be based on impact-not just aligned to the medical strategy, but also to changes in the clinical environment, ultimately benefiting patient care, as well as contributing to the overall brand strategy.

Above all else, one of the main responsibilities of the Medical Director is people management. In a 2003 interview, Steve Jobs accurately said "great things in business are never done by one person, they are done by a team of people" [16]. The ability to hire a team of high-potential individuals and then inspire them to perform beyond their own expectations is a key capability of achieving great impact that is felt both internally and externally. The power to inspire and challenge, while still nurturing sufficiently to allow growth, is a delicate balance that needs to be prioritised and should be allocated sufficient time to ensure a high-performing team. This, however, is often overlooked, as meeting the needs of cross-functional teams tends to take priority. However, if cross-functional teams decide the priorities of the Medical Affairs team, it's very easy for the team to fall into a category of 'supporting function'. The Medical Affairs team needs to have a different approach to ensure they deliver significant impact that cannot be achieved by others and are perceived as irreplaceable. A highly capable and empowered team will lead to a strong partnership relationship with cross-functional teams, with influencing power to align other functions to support medical strategic priorities, obtain resources to execute these priorities and deliver impact that cannot be delivered by other functions, therefore gaining partnership and investment to the function.

In order to achieve this impact, the Medical Director needs to be able to identify and provide high-level guidance on what should be the prioritised focus for their team. This requires the ability to identify clear brand strategic priorities, key success factors, key challenges for the brand and the activities that most efficiently and successfully address them. An impactful drug pipeline often means a more difficult launch preparation, as it requires a significant mindset shift and environmental changes. Team focus, under the Medical Director's guidance, on impactful activities and medical resource investment is crucial to ensure changes that can easily be felt both internally and externally. This will help establish a reputation in the Medical Affairs team's process that increases the ability to influence and leads to further impact and irreplaceability.

In summary, a successful Medical Director needs not only to be able to prioritise what is impactful and influential themselves but develop and lead a team that is able to do the same. In return, they will gain respect and deliver impact that is recognised both internally and externally.

\subsection{Think Win-Win ${ }^{\oplus}$ : Enterprise Leadership}

According to McKinsey's A Vision for Medical Affairs in 2025 report, after a period of time, "pharmaceutical company CEOs will come out of Medical Affairs" [3]. This is a great ambition to have from a functional point of view, but it will probably not be a smooth journey for individuals in practice. The key challenge for Medical Directors is to shift from a siloed to an enterprise-wide mindset and start acting in the best interests of the enterprise, rather than a Medical Affairs function only. The Medical Director must be accountable for the success of the enterprise as a whole and conversant with the full business cycle, as well as interpret research and development, science, medical practice and patient needs for cross-functional team members and stakeholders [13].

Irrespective of the fact that Medical Affairs has transitioned to an integrated strategic role within the organisation, the 'us versus them' attitude and differential treatment may still be present as a result of existing corporate silos and the legacy of the on-demand and supporting nature of the function in the recent past. Consequently, instead of contributing to and leveraging the performance of other departments and teams, and leading their team to do the same, the Medical Director's perspective and effectiveness are driven by their individual and teams' objectives only. In addition, talent development in Medical Affairs and enterprise collaboration have often taken a back seat to 'getting things done'. From a talent management standpoint, the priority has been on leveraging domain expertise and promoting vertically within silos. As a result, Medical Directors often had great depth, but little breadth across the organisation [17]. Therefore, medical leaders who seek out professional development opportunities that enhance both their interpersonal, management and 'business' skills—-such as accounting, finance and 
planning-are more likely to succeed as enterprise leaders [18].

Based on this knowledge and practical experience from the flagship talent development programme specifically designed to develop future Medical Directors in AstraZeneca's International region, iStep Up to Leadership, we aim to effectively address the enterprise leadership habit (Fig. 3). This enterprise leadership habit will help iStep Up to Leadership graduates to be successful when they progress to leadership roles. Whether at individual or team development levels, we must focus on the three most important behaviours that distinguish traditional leadership from enterprise [4, 19]:

1. They take from, and give to, their peers.

2. They push, and pull, team contributions.

3. They facilitate, and don't direct, team performance.

The best example we have to illustrate enterprise leadership in action in AstraZeneca's International Medical team is our Emerging Markets Health Innovation Hubs Networkpart of the global A.Catalyst Network of innovation hubs [20]. Thanks to the Medical team members behind the concept coordinating cross-functional input across the enterprise, the Health Innovation Hubs bring together traditional (patients, health care practitioners, academia, governments and policy makers) and non-traditional (technology and pharmaceutical industries, ecosystem builders, investors and entrepreneurs) partners within emerging markets to reimagine how we can accelerate innovation, increase access to health care and improve outcomes for patients and society at large.

In conclusion, and referring back to McKinsey's A Vision for Medical Affairs in 2025 report, published more than a decade ago, Medical Directors aspiring to a CEO role (the ultimate manifestation of enterprise leadership) may want to consider the following suggestions [3]:

1. Make your intentions known.

2. Groom your successor.

3. Request a title change.

4. Get your Master's degree.

5. Pursue professional development opportunities.

6. Consider leaving the organisation.

7. Talk with your family [3].

\subsection{First Understand, Then Be Understood ${ }^{\circledR}$ : Communication and Behavioural Change}

According to Stephen Covey, the key to successful communication and being heard lies in understanding the other party by listening effectively [6]. Listening is often overlooked, and really focusing on what's being said can be a challenge due to limited mental space and the number of interruptions and distractions we face every day. People often perceive themselves to be good listeners, but research [21] suggests that most people only remember $25-50 \%$ of what they hear. Medical Directors are often faced with the additional challenge of having a high span of control and limited time with each stakeholder.
Fig. 3 iStepUp to Leadership 2.0: Developing international medical leaders that create the future

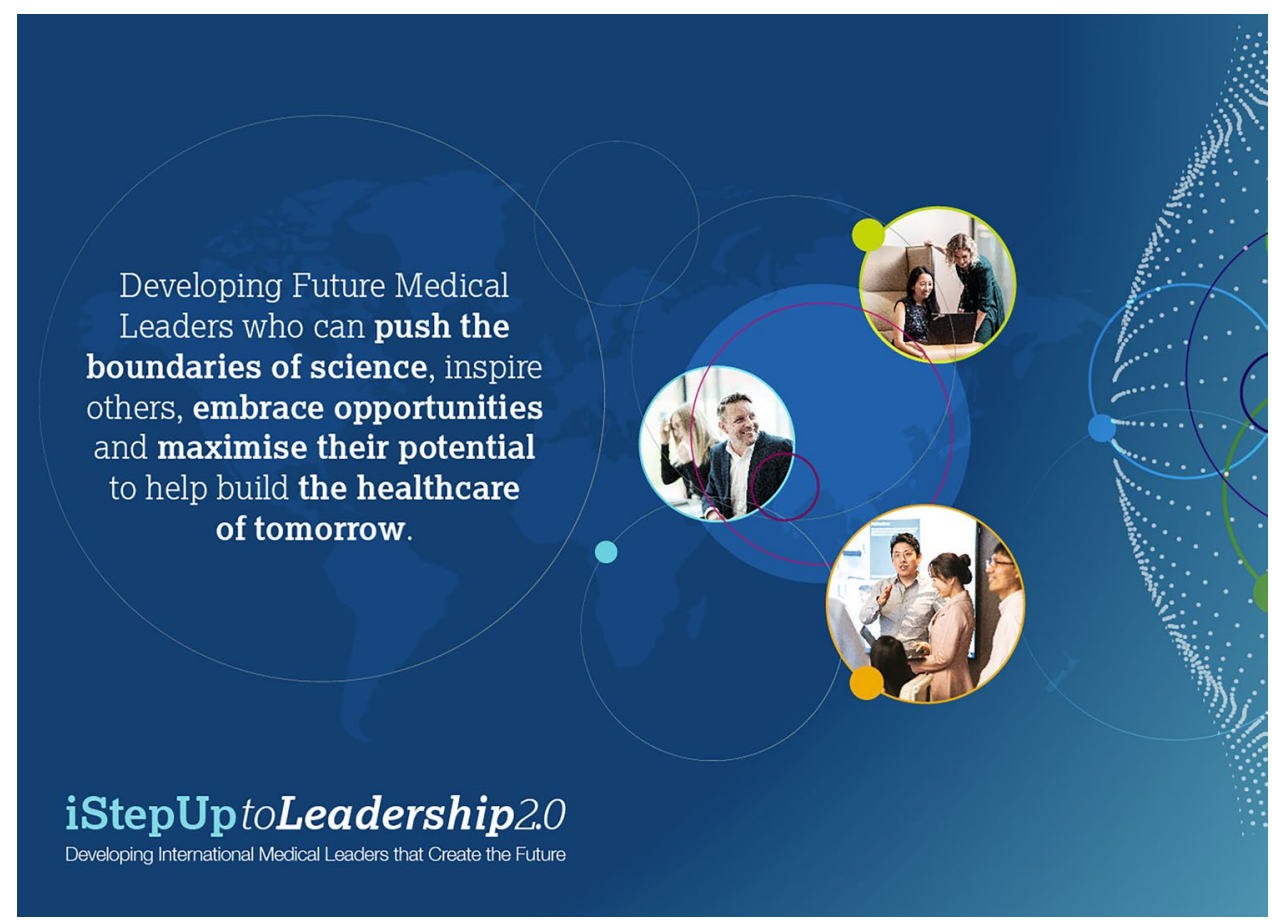


Typically, successful Medical Directors take the time to listen to their stakeholders and their teams, which enables them to connect and build trust. The general tendency in communication is to get our message across quickly, rather than taking the time to listen attentively to the other party. The purpose of listening should be to understand and not to reply, but in most cases, this is a challenge that requires behavioural change and involves being highly aware of our own senses and emotions in order to control them. In some cases, we might also have a predetermined judgment on the subject, which makes it harder for us to focus on the conversation. It is important to keep an open mind and to be aware of our own prejudices. In the instances that we hear a message contradictory to our ideas or beliefs, it can be easy to react and respond to what is being said, but it is critical for us to focus and understand the other side, rather than jump to conclusions. This includes controversial views and challenges to our conversations. It is good practice to maintain a holistic view and be prepared for difficult situations we may face in our interactions.

As people management is one of the key responsibilities of the Medical Director, performance development is one of the key processes that relies on effective communication. Medical Directors who have regular coaching conversations with their teams are able to help them stretch and grow, by asking the right questions and understanding the employee's perspective. Engagement, being present and reflecting on what has been said can help us understand each other, leading to more effective communication and improving the overall performance of the team.

\subsection{Synergise ${ }^{\circledR}$ : Partnering}

Synergy is the habit of creative co-operation. It is a combination of teamwork, open-mindedness and finding new solutions to old problems. Synergy is often a process by which team members bring all their experiences and expertise to solve problems, but sharing common values and challenges, as well as areas of disagreement, is important. Our objective of putting patients first and ensuring the best patient outcomes and experiences is the foundation of a synergistic partnership. An important aspect of this is to value diversity-finding synergies can help us not only to solve old or current problems but create new opportunities for all parties.

Medical Directors have two distinct sets of stakeholdersinternal stakeholders, including cross-functional team members (Commercial, Finance, Human Resources, Regulatory Affairs, Clinical Development, Health Outcomes, regional and global leaders in both Medical and other functions) and external stakeholders, which includes health care providers, medical societies, payer and insurance agencies, public agencies and government, patient and caregiver groups, health care activities, the lay community and medical teams from other organisations. Developing robust partnerships with internal stakeholders helps Medical Directors exceed their objectives and achieve organisational success. Successful partnerships with external stakeholders are vital in policy shaping and the creation of a robust health care system. This may include evidence generation in assessing value outcomes, real-world settings and investigator-initiated research. Additionally, in recent times, diagnostics, device manufacturers and technology providers have also emerged as key external stakeholders in our journey to create new solutions.

There are two primary ways of creating more synergy and building partnerships:

Complete two tasks with one action: This is highly relevant with internal stakeholders. Medical Directors must understand the cross-functional teams' point of view, objectively downplay their personal views and identify areas where there is more agreement than disagreement. While doing so, Medical Directors should keep an open mind to learning new things from different parties; for example, some functions, such as Commercial, have strong skills in project management and branding, while finance teams typically have excellent analytical skills. Medical teams have an in-depth knowledge of the patient journey and the needs of patients-everyone brings their own perspective to the table. Medical Directors must have the leadership skills to bring all stakeholders together and empower other colleagues to maximise their own skills to achieve the desired results. They must have the ability to use their emotional quotient skills to work effectively cross-functionally and be ready to translate complex science to the partner's language. While doing so, Medical Directors must put their 'functional hats' away and have a clear understanding of enterprise leadership. Readiness to learn new skills, understand their own limitations and find solutions are key attributes of successful Medical Directors.

Treating health care as an interconnected system [22]: Health care has evolved in such a way that multiple players coexist to create defined networks. Many of these players belong to slightly different areas of pharmaceuticals (e.g. pharmaceutical devices or diagnostics). Additionally, the network of health care providers, regulators, reimbursement agencies, patients and communities are also now interlinked. Finally, there are new players, such as those providing data analytics, technology providers and digital media experts, who also have a prominent role to play in the delivery of health care. In certain circumstances, traditionally competitive pharmaceutical companies may even come together as partners for specific tasks and activities. The role of a Medical Director is to identify these networks, connect the dots and work towards sustained delivery of health care. Medical Directors create this ecosystem and promote healthy knowledge sharing between various partners. They must look at 
this system as a strategic long-term tool, not merely one to achieve short-term objectives. In order to successfully synergise with different partners, Medical Directors must have a clear project plan, while keeping their minds open to new ideas. It also means synergising with skill sets available in the external world, rather than just creating those skill sets internally. Medical Directors must select the right set of partners with common values and beneficial skill sets.

The A.Catalyst Network is a concept that connects this variety of stakeholders. The scope of each hub is different in every country, though the principles of creativity, collaboration and value creation are shared. It has become a sustainable forum for the exchange of ideas and creating solutions in patient care. Hubs in Russia, Taiwan, India and China, to name a few, have already demonstrated value nationally, as well as in other countries.

\subsection{Sharpening the Saw ${ }^{\circledast}:$ Scientific and Technological Leadership}

In today's rapidly evolving world, scientific advances are happening more quickly than ever before, impacting our approach to patient identification and the selection of preventative techniques and management. In recent years, technological advances co-exist with scientific advances and are often interlinked. Medical Directors, as scientific experts, should stay informed of such scientific advances, especially in the therapy areas they operate in, and should always keep themselves updated on these developments. A Medical Director should also be able to connect the upcoming science and the latest developments in medical practice with technological advances inside and outside the health care setting, applying advancements in order to accelerate the adoption of scientific innovation with a sustainable approach. This habit implies a truly cross-functional mindset, while at the same time requires a solid scientific and medical background to maintain focus on the final objective of delivering innovative medicines to a broad population [23].

Practising the habit of being a scientific-technological leader can be divided into three phases:

(i) Managing the latest scientific data and understanding gaps in the ecosystems to make innovation adoptable and sustainable, leveraging data analytics and artificial intelligence (AI) Cumulative big scientific data is probably the best example of where machine learning can be applied. Medical Directors should leverage new technologies, such as AI, and apply cutting-edge scientific knowledge. However, health care ecosystems offer both the rich opportunity and challenging mission of analysing big data available for the application of AI. Data from electronic medical records (EMRs), health economics and patient-reported outcomes can all be pulled into a machine learning algorithm to generate insights on patient behaviours, patient risks and effective interventions. This use of technological advances in situational diagnosis is the first step towards a digital agile mindset.

(ii) Keeping updated and connected with innovative technological options in health, but also with innovation from other industries, by establishing a broad spectrum of partnerships and fostering connections with health ecosystems Evolving from a 'doing digital' to a 'being digital' approach includes embracing the mindset, principles and opportunities that digital health brings to create new value for patients, HCPs and health ecosystems. To make this evolution a reality, the Medical Director should lead the mental integration between medical and information technology/digital teams, encouraging continuous interactions in internal forums. They should also encourage colleagues to share the latest advances from both functions. In addition to scientific congresses and forums, attending external forums and exchange meetings in the technological and innovation arena is also a best practice to adopt as a futurist Medical Director.

(iii) Integrating leading technologies with a patient-led mindset to drive better patient outcomes and experiences through innovation In this phase, HCP experiences can be synergised with end-to-end platforms. This includes putting the application of knowledge acquired in the previous phases into practice to support patient identification, early diagnosis and better clinical interventions that result in improved outcomes, adequate disease management and control and improved health resource utilisation.

As an example, to address the lack of early diagnosis of lung cancer in many emerging markets with few national screening programmes in place, we launched a tool leveraging AI-based technology that can help identify possible lung cancer cases based on radiological tests, such as thorax computerised tomography (CT) scans or X-rays. Thorax $\mathrm{X}$-rays are widely available and economical, but not usually digitised, and $19-26 \%$ of lung nodules on chest X-rays are missed during the first readings (PCS), while for board-certified thoracic radiologists, detection performance is $>80 \%$. AI-based systems have shown to improve nodule detection to accuracies ranging from 80 to $90 \%$ [24-26]. In the last year, we have partnered with Qure.ai, a provider of AI platforms, to implement a solution that can be applied from mobile phones and directly on X-ray machines. Using this AI application for analysing analogue and digital X-rays, we aim to aid general practitioners (GPs) and physicians working in primary care settings to identify incidental lung nodules, so that individuals with suspected cases can then undergo specific pathological tests to confirm or rule out lung cancer. This project has recently started to be rolled out across many emerging markets [27].

$\mathrm{AI}$ is not the only technology available. In a model where we partner with a technology start-up from India, Tricog, 
patients with chest pain undergo a digital electrocardiogram (ECG), which is then rapidly analysed to confirm whether it is acute coronary syndrome (ACS) or not. If ACS is confirmed, the patient is then guided to the nearest available catheterisation laboratory (cath lab) using smartphone technology. Thanks to this process, we expect to reduce symptom-to-door time, and since the cath lab is made aware of the patient ahead of their arrival, even the door-to-needle time may be reduced. This may give the patient a chance of better clinical outcome.

Finally, digital platforms are a key tool and a perfect example of how technology has been leveraged to accelerate science through collaborative research and educational projects. We are currently partnering with BITGENIA, a spin-off of CONICET (the main entity for researchers in Argentina), to launch a collaborative biobank, EMR and genomic platform that connects laboratories belonging to research institutions across Latin America. The objective is to enhance translational research capacity and capabilities with a more efficient approach, joining efforts to obtain faster results from broader populations for diseases with very low incidence.

Medical Directors have the responsibility to translate science into better outcomes and experiences for patients. Today, we have a world of possibilities to leverage technological advances that could be adopted as catalysers of upcoming paradigms.

\section{7+ Habit: Building the Team}

We have discussed seven very relevant habits... now let's move to the final, very important, habit for Medical Directors: building the team. Why is building a team a fundamental habit for Medical Directors? First, because nobody succeeds alone, nor fails alone, but also, and most importantly, because belonging to a team makes all the difference in times of celebration and especially when recovering from setbacks [28].

There is no set formula to build a successful team, but we do have some learnings from developing a group of talented people into a strong and respected medical team.

Leadership skills alone are not enough to build a teamtwo key sets of skills are needed. Following Gonzalo Noya's analogy, and comparing the team with a guitar, within a team, we have six strings split in two groups: at the bottom of the guitar are the bass strings that we can compare with hard or technical skills, and at the top, the guitar has treble strings, equivalent to soft or leadership skills. We expect each string to sound perfect individually, but it is fundamental that all the strings are tuned together to deliver a harmonious sound. The same goes for a successful team.
Let's look 'string by string' at how we can stay in tune and work in harmony [28].

The first string is the big objective: something your team collectively wants to achieve. In our case, after years of working in isolation, our objective was to put AstraZeneca's International Medical team on the global map, ultimately building internal and external stakeholders' confidence in our capability to deliver and to transform our brand.

The second string is people. Successful teams are made up of people with complementary talents who are committed to the big objective. This is the string Medical Directors should pay most attention to, as it is the guitar in itself. Although the notes are different, they should pitch together-the guitar should be tuned so that all the strings are in perfect harmony. And sometimes a string must be changed to maintain the overall quality of the sound; as a leader, it is the Medical Director's responsibility to identify this and action it.

The third string is tuning-the equivalent of setting rules, tracking progress, recognising merit and correcting any deviations.

The bass tones connect us with a common purpose, beyond the objective. The fourth string is the mission, in our case, translating our scientific leadership into actions that guarantee better outcomes for more patients. Our mission is the reason we wake up every day and go to the office or the airport. This is what makes us happy when we achieve our goals, but also what makes us resilient in the event of setbacks. Having a strong mission is fundamental to building a team as it attracts the right people.

The fifth string is values. Shared values are what bond a mix of people together; all members should embrace the values to ensure they are aligned with the other strings. Values are about how you achieve your goals and provide the answers when you have doubts.

Last but not least is the sixth string: trust. With this string, a successful team will achieve maturity. When team members are trusted by one another, it is like playing a tune by heart. This happens when you know where your colleagues will be for the next pass, for the next sound. You can improvise, although this is probably the most difficult aspect to achieve. However, when trust has truly been established, the team is ready for anything.

There is one other aspect to introduce: the producer. The producer provides the external view that brings an additional level of achievement. Because the producer is interested in the success of the team but comes from a different place and can provide constructive criticism, they are perfectly positioned to challenge the Medical Director with a win-win objective. In the case of the Medical Director, the producer will act as a company president. In the case of Regional Medical Directors, the producer will act as a business partner. The Beatles allowed George Martin to challenge their 
music, and with him, they became one of the most influential bands of all time.

This is the last habit we wanted to share: let others comment, challenge and criticise. It is the most difficult skill but one that makes the difference between excellent and exceptional—and we cannot accept less... our patients deserve it.

This final habit may be the most important habit for a Medical Director: to build a team with a clear ambition, talented and complementary members, high standards, a common purpose, solid values and trust in each other. This takes time and after a while the team will be playing well together. However, to take the team to the next step, something else is required to achieve 'the perfect pitch'.

But what is the Medical Director's role within the team? As a leader, it's important to be a strong figure, but at other times, to demonstrate a warm and approachable nature, so that team members feel comfortable enough to ask for help when they need it. Being a Medical Director is all about managing the balance between empowerment and support.

\section{Developing and Enriching the Habits}

Until now, we have discussed all the habits that are necessary for Medical Directors to succeed. However, this requires resilience and clear priorities in order to succeed on a daily basis. Medical Directors need to be the team energy administrator. This is about taking the time to renew and refresh the four main dimensions of nature-physical, mental, emotional and spiritual. This eventually helps us to be more effective in our life's work-working smarter, not necessarily harder.

As Medical Directors, keeping abreast of new developments is rewarding but can also be exhausting. Staying up-to-date with the external world is a top priority for Medical Directors so they need to take the time to recharge regularly. Medical Directors have to focus on the four domainsphysical, mental, spiritual and emotional. These domains are interconnected and can influence each other, allowing us to synergise and enabling us to do more in less time.

The physical domain is about ensuring physical wellbeing, strength and vigour. Medical Directors will benefit from focusing on adequate exercise, healthy eating and maintaining a good sleep-wake cycle-this could take as little as $30-40 \mathrm{~min}$ a day.

The mental domain is equally important as Medical Directors complete a lot of 'mind work'. A good way of recharging the mental domain is to give our mind something different to think about, besides what it usually focuses on at work, supporting the generation of new insights and ideas. Some examples are academic pursuits, attending lectures on varied topics, joining discussion groups and meeting people from different backgrounds.

The spiritual domain generates the sense of purpose in life. In today's world, where Medical Directors have to balance science, patient care and business, it is important to keep the spiritual domain at the top of the agenda. Medical Directors should enhance their spiritual wellbeing by working on their mission statement, practicing self-examination, identifying their self-purpose and aligning their actions to that purpose. This will give Medical Directors more clarity of purpose as well as energy to do unconventional things. The experiences of the last year has made the spiritual domain more relevant than ever before.

The fourth component, emotional, is about interacting with other human minds to refine ideas and learn new ones. This includes meeting new people (as opposed to networking, which has a specific objective), spending more time
Fig. 4 iPeople4 People: Together for one another

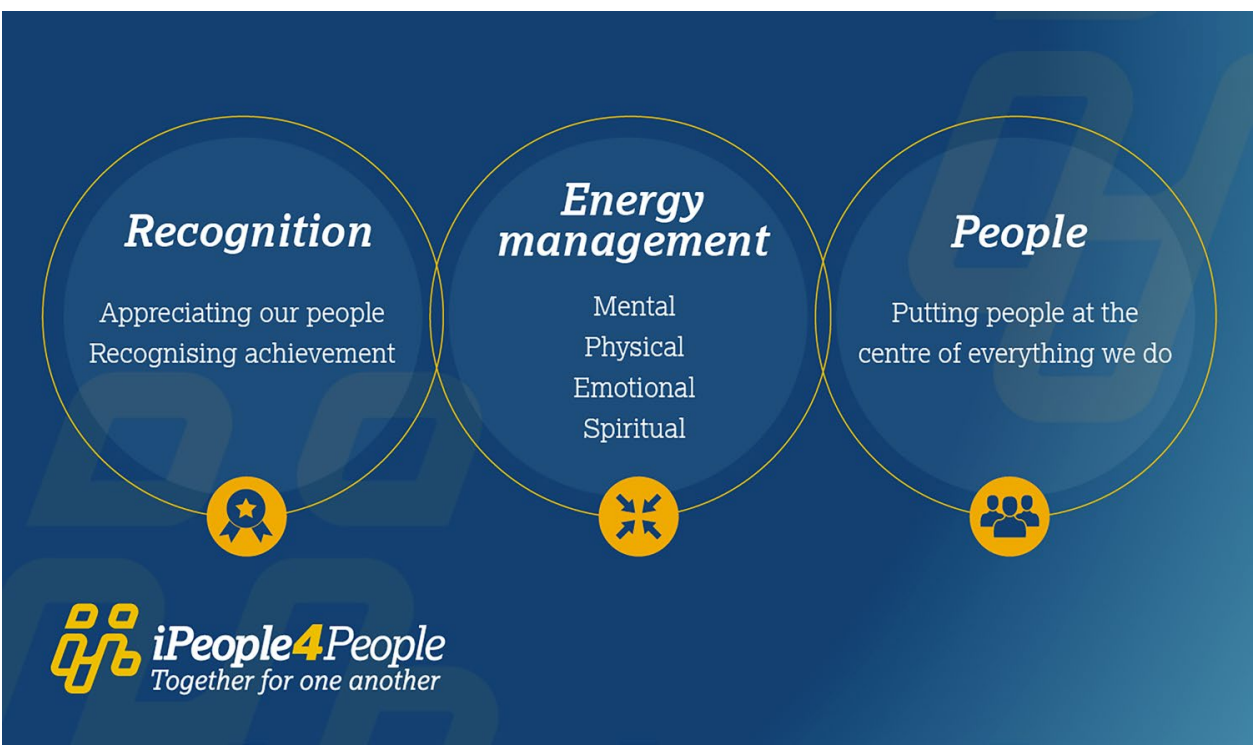


with family and friends, learning new skills from people in different professions and understanding how the world is changing in other fields.

With these domains in mind, our team launched the International People for People (iP4P) programme this year (Fig. 4). iP4P includes training for Medical Directors on all four domains, ensuring that they prioritise this over their daily activities. Medical Directors are embedding all of these concepts into their professional and personal lives and can then cascade the programme to their teams of Medical Science Liaisons (MSLs) and other medics. Finally, the Medical Director community creates a forum for sharing best practice where other teams across emerging markets share their experiences and provide support on these domains. We are eager to assess the impact of this programme on the wellbeing of our teams.

\section{Conclusion}

Stephen Covey's The 7 Habits of Highly Effective People ${ }^{\circledR}$ can be contextualised for Medical Directors. Each of the habits has specific corresponding areas for Medical Directors to focus on. The habits are complementary to each other and an integral part of the leadership journey. Maintaining optimum health in physical, mental, emotional and spiritual domains is a good way of sustaining these habits on a daily basis. As Medical Directors, this will help propel us in creating the Medical Affairs teams of tomorrow.

Acknowledgements The opinions expressed in this article are those of the authors and not necessarily those of AstraZeneca. ㅅ A trademark of Franklin Covey Co.

\section{Declarations}

Funding We have not received any funding for this manuscript. AstraZeneca International has paid for the fees related to the open access of the paper.

Conflict of Interest All authors are permanent employees of AstraZeneca. The thoughts and statements expressed within this article are written in the capacity of medical affairs professionals and not as AstraZeneca employees.

Ethics Approval Not applicable.

Consent to Participate Not applicable.

Consent for Publication Not applicable.

Availability of Data and Material Not applicable.

Code Availability Not applicable.

Author Contributions Every author was responsible for drafting individual sections of the manuscript. All authors collectively take com- plete responsibility for the manuscript in its entirety, have approved the final version of the manuscript and are accountable for the thoughts presented in the manuscript.

Open Access This article is licensed under a Creative Commons Attribution-NonCommercial 4.0 International License, which permits any non-commercial use, sharing, adaptation, distribution and reproduction in any medium or format, as long as you give appropriate credit to the original author(s) and the source, provide a link to the Creative Commons licence, and indicate if changes were made. The images or other third party material in this article are included in the article's Creative Commons licence, unless indicated otherwise in a credit line to the material. If material is not included in the article's Creative Commons licence and your intended use is not permitted by statutory regulation or exceeds the permitted use, you will need to obtain permission directly from the copyright holder. To view a copy of this licence, visit http://creativecommons.org/licenses/by-nc/4.0/.

\section{References}

1. Coulton E, Crowley J, Rhee B. Good science: the new role of medical affairs in an outcomes-focused world. 2016. https://www. slideshare.net/accenture/good-science-the-new-role-of-medicalaffairs-in-an-outcomesfocused-world. Accessed 18 Jun 2021.

2. Plantevin L, Schlegel C, Gordian M. Reinventing the role of Medical Affairs. 2021. https://www.bain.com/insights/reinventing-therole-of-medical-affairs/ Accessed 18 Jun 2021.

3. Evers M, Ghatak A, Suresh B. A vision for medical affairs in 2025. 2020. https://www.mckinsey.com/ /media/mckinsey/indus tries/pharmaceuticals\%20and\%20medical\%20products/our\%20ins ights/a\%20vision $\% 20$ for $\% 20$ medical $\% 20$ affairs $\% 20$ in $\% 202025 /$ a-vision-for-medical-affairs-in-2025.pdf. Accessed 1 Jul 2020.

4. Bedenkov A, Rajadhyaksha V, Beekman M, et al. Developing medical affairs leaders who create the future. Pharmaceut Med. 2020;34(5):301-7. https://doi.org/10.1007/s40290-020-00351-y.

5. Stonier P, Gillen D. The Medical Department. In: Griffin JP, editor. The Textbook of Pharmaceutical Medicine. 6th edn. London: Wiley-Blackwell; 2009. pp. 285-95. https://doi.org/10.1002/ 9781444317800.ch10.

6. Covey S. The 7 habits of highly effective people. Free Press; 1989.

7. Cran C. The future of work needs leaders with these skills. 2018. Available from https://www.siliconrepublic.com/advice/leade rship-skills-future-of-work. Accessed Jun 2021

8. Souba W, Souba M. How effective leaders harness the future. Acad Med. 2018;93(2):166-71. https://doi.org/10.1097/ACM. 0000000000001955.

9. Wolf G. Steve Jobs: the next insanely great thing. 1996. https:// www.wired.com/1996/02/jobs-2/ Accessed 1 Jul 2020.

10. Fast Company. 4 commonly overlooked reasons why creative leaders succeed. 2016. https://www.fastcompany.com/30558 38/4-commonly-overlooked-reasons-why-creative-leaders-succe ed. Accessed 1 Jul 2020.

11. Harvard Business Review. The 4 kinds of leaders who create the future. 2017. https://hbr.org/2017/12/the-4-kinds-of-leaders-whocreate-the-future. Accessed $1 \mathrm{Jul} 2020$.

12. Brodherson M, Heller J, Perrey J, et al. Creativity's bottom line: How winning companies turn creativity into business value and growth. 2017. https://www.mckinsey.com/business-functions/ mckinsey-digital/our-insights/creativitys-bottom-line-how-winni ng-companies-turn-creativity-into-business-value-and-growth. Accessed 1 Jul 2020. 
13. Suresh B, Buxton C, Ferrer J, et al. Managing talent in the Medical Affairs function. 2013. https://www.mckinsey.com/ /media/ mckinsey/dotcom/client_service/pharma\%20and $\% 20$ medical $\%$ 20products/pmp\%20new/pdfs/managing_medical_affairs_talent. ashx. Accessed 1 Jul 2020.

14. Modern Mechanix. The making of Macintosh - an interview with The Macintosh Design Team (Feb, 1984). 2008. http://blog.moder nmechanix.com/the-making-of-macintosh-an-interview-with-themacintosh-design-team/. Accessed 1 Jul 2020.

15. Covey, SR [@StephenRCovey]. The key is not to prioritize what's on your schedule, but to schedule your priorities. 2021. For full video: https://youtu.be/zV3gMTOEWt8/ [Tweet]. Twitter. 7:55pm 24 August 2017. https://twitter.com/stephenrcovey/status/90079 3825156894721. Accessed 14 Jun 2021.

16. CBS News. Steve Jobs and the Beatles. 2003. https://www.cbsne ws.com/video/steve-jobs-and-the-beatles/. Accessed 1 Jul 2020.

17. Korn Ferry. Building broad enterprise leadership capacity. 2021. https://www.kornferry.com/insights/this-week-in-leadership/build ing-broad-enterprise-leadership-capacity. Accessed 1 Jul 2020.

18. Tyler JL. Vice president of Medical Affairs - moving on up to CEO? Phys Exec. 1999;25(5):20-4.

19. CEB Global. Are your leaders driving "one-company" results? 2015. https://andersonyorke.com/docs/CEB\%20-\%20Are\% 20Your\%20Leaders\%20Driving\%20One-Company\%20Results. pdf. Accessed 1 Jul 2020.

20. AstraZeneca. Health innovation hubs in emerging markets: creating integrated science ecosystems. 2020. https://www.astrazeneca. com/partnering/partnering-case-studies/health-innovation-hubsin-emerging-markets.html. Accessed 1 Jul 2020.
21. Dale E. Audiovisual methods in teaching. 3rd ed. New York: Dryden Press; 1969.

22. McKay B, McKay K. The 7 habits: Synergy (beyond the eyerolling buzzword). 2021. https://www.artofmanliness.com/artic les/the-7-habits-synergize-beyond-the-eye-rolling-buzzword/. Accessed 15 May 2021.

23. McKay B, McKay K. The 7 habits: Sharpen the saw. 2021. https:// www.artofmanliness.com/articles/the-7-habits-sharpen-the-saw/. Accessed 15 May 2021.

24. Nam JG, Park S, Hwang EJ, et al. Development and validation of deep learning-based automatic detection algorithm for malignant pulmonary nodules on chest radiographs. Radiology. 2019;290:218-28.

25. Ausawalaithong W, Marukatat S, Thirach A, et al. Automatic lung cancer prediction from chest X-ray images using deep learning approach. 2018; arXiv:1808.10858v1.

26. Kermany DS, Goldbaum M, Cai W, et al. Identifying medical diagnoses and treatable diseases by image-based deep learning. Cell. 2018;172:1122-31.

27. Business Standard. AstraZeneca, Qure.ai to bring AI solutions to detect lung cancer. 2020. https://www.business-standard.com/ article/international/astrazeneca-qure-ai-to-bring-ai-solutionsto-detect-lung-cancer-120120700992_1.html. Accessed 26 May 2021.

28. Noya G. ALGO + GRANDE: El poder del EQUIPO para lograr lo imposible (Something Bigger: the power of the team to achieve the impossible). Uruguay: Xn Publishing; 2020. 